\title{
Criar Éducação
}

\section{“PARAÍSO LUSO-TROPICAL”. REDEMPTION, DE MIGUEL GOMES}

Resumo: A média-metragem Redemption (2013), de Miguel Gomes, é composta por quatro cartas ficcionais de políticos europeus. Na primeira missiva, datada de 1975, Pedro Passos Coelho escreve, de uma aldeia de Trás-os-Montes, aos pais que ficaram em Angola. O texto de 2013 traça uma continuidade geográfica e histórica entre três espaços-tempos: o mundo rural do Portugal revolucionário de janeiro de 1975; o espaço colonial prestes a alcançar a independência; o País em 2013. A comunicação debruça-se sobre o modo como a narrativa fílmica desloca a visão da África colonial portuguesa e a sua representação cinematográfica enquanto "paraíso tropical", expressão de Amílcar Cabral. Através de uma análise das formas fílmicas de Redemption, o texto aborda o processo de redistribuição espácio-temporal dos topoï coloniais e a emergência de novas constelações audiovisuais como um espaço crítico das representações do passado e uma sintomatologia do presente.

Palavras-chave: Pós-colonialismo; relacionismo e perspetivismo; antropologia visual; anarquivo; intertextualidade; representações coloniais; crise.

Abstract: The average film Redemption (2013), Miguel Gomes, is composed of four fictional letters of European politicians. In the first letter, dated 1975, Pedro Passos Coelho writes, a village of Tras-os-Montes, to parents who were in Angola. The text of 2013 outlines a geographical and historical continuity of three space-times: the rural world of revolutionary Portugal January 1975; the colonial space about to achieve independence; the country in 2013. The Communication focuses on how the filmic narrative shifts the view of the Portuguese colonial Africa and its cinematic representation as "tropical paradise", Amilcar Cabral expression. Through an analysis of filmic forms of Redemption, the text deals with the spatio-temporal process of redistribution of colonial topoi and the emergence of new audiovisual constellations as a critical space of representations of the past and a symptom of this.

Keywords: Post-colonialism; relationism and perspetivismo; visual anthropology; anarquivo; intertextuality; colonial representations; crisis.

Confundindo, talvez inconscientemente, realidades biológicas e necessárias com realidades socioeconómicas e históricas, Gilberto Freyre fez de todos nós que vivemos nas colónias-províncias de Portugal os ditosos habitantes de um paraíso Luso-tropical. ${ }^{2}$

\footnotetext{
1 Doutorada em Estudos Cinematográficos e Audiovisuais pela Universidade Sorbonne Nouvelle - Paris 3, Raquel Schefer é docente, realizadora e programadora de cinema.

2 Cabral, Amílcar. 1969. Prefácio a The Liberation of Guiné: Aspects of an African Revolution, de Basil Davidson. Harmondsworth, Baltimore e Ringwood: Penguin, p. 9.

UNESC, Criciúma, v. 5, n¹, janeiro/Junho 2016. Criar Educação - PPGE - UNESC
} 


\section{Criar Éducaçãa}

Redemption, de Miguel Gomes, filme de montagem de 2013 construído integralmente com imagens de arquivo de diferentes origens e estatutos, reúne cartas ficcionais de quatro políticos europeus: Pedro Passos Coelho, Silvio Berlusconi, Nicolas Sarkozy e Angela Merkel. Este artigo centra-se na primeira epístola, assinada por Passos Coelho e datada de 21 de janeiro de 1975, meses depois do 25 de Abril e do reconhecimento da auto-determinação da Guiné-Bissau e pouco antes da independência de Moçambique e de Angola, em junho e novembro daquele mesmo ano. Nela, o atual primeiro-ministro português, nascido em 1964 e que então vivia em Vale de Nogueiras, aldeia de Trás-os-Montes, escreve uma carta aos pais, que deixara em Luanda.

De Angola a Vale de Nogueiras. A fabulação textual e a montagem unificam dois espaços-tempos: o mundo rural nortenho do Portugal revolucionário e o espaço colonial prestes a alcançar a independência. Na primeira carta, o tratamento da questão colonial assenta fundamentalmente na aproximação entre o território colonial e o espaço rural português. Dois espaços-tempos ao qual se agrega um terceiro eixo espácio-temporal, o País em 2013, quando a crise - ou o fracasso - do projeto europeu vem resignificar aquele momento de estertor do império. A oposição "nós" / "eles" é delineada narrativamente pela voz-off em primeira pessoa, com o condicional como tempo enunciativo dominante. $\mathrm{O}$ "eles, o "outro" que se opõe ao núcleo familiar, afetivo, cultural e, mesmo, civilizacional no qual o narrador se inclui não é tanto o africano, mas o português da metrópole, daquele Portugal "de gente pobre e feia a passear uns bois esqueléticos e sem ter nada que comer ao mata-bicho", como descrito pela voz-off. O lugar - ou o não-lugar - da voz começa, deste modo, por questionar o binarismo do sistema colonial e tripartir as posições enunciativas, o que sugere a possibilidade de uma rotação - e de uma permuta da perspetiva: o primeiro episódio do filme desorganiza a cartografia das relações de proximidade e distância entre o "aqui" e o "ali", o "mesmo" e o "outro", relações que são parcialmente invertidas e temporariamente suspensas. Redemption é, essencialmente, uma obra sobre o "aqui" e o "mesmo", mas também um exercício de imaginação sobre a forma como o "aqui" e o "mesmo" poderiam ser vistos pelo "ali" e pelo "outro".

Neste texto, gostaria de examinar de que modo a heterogeneidade e a multitemporalidade das fontes discursivas e do material de arquivo, assim como a montagem, a enunciação e os processos de ressemantização da imagem contribuem para uma deslocação da visão da África colonial portuguesa e da sua construção afetiva e teórica, ainda hoje vigente, como um "paraíso luso-tropical" (Cabral 1969, ix), expressão UNESC, Criciúma, v. 5, n¹, janeiro/Junho 2016. Criar Educação - PPGE - UNESC 


\section{Criar Éducaçãa}

irónica de Amílcar Cabral visando o Luso-tropicalismo de Gilberto Freyre. Tal deslocação aponta - e, em certo sentido, concretiza - a hipótese de uma redefinição da relação entre o sujeito da enunciação e o sujeito do enunciado, no sentido de um relacionismo contrário à unidirecionalidade e à ausência de contracampo do olhar colonial.

Em 1961, no prefácio de Jean-Paul Sartre à primeira edição de Les damnés de la terre, de Frantz Fanon, o filósofo afirma que os colonizadores deixaram de ser sujeitos históricos e se converteram em objetos da história. Dá-se uma permuta de perspetivas e uma transferência da neurose colonial ao colonizador, hipótese que atravessa a teoria psiquiátrica de Fanon. Pele negra, máscaras brancas, mas também algo do colonizado que impregna e fica no colonizador, o que as formas "epistémicas de incerteza e claridade" do poder colonial, descritas por Anne Laura Stoler (Stoler 2010, 43), tão bem denotam. Citando Sartre, França, "em 1961, o nome de uma neurose..." (Sartre 2002, 41) e "...os europeus estão a ser descolonizados... estamos a extirpar, numa sangrenta operação, o colono que vive em cada um de nós. Devemos voltar o olhar sobre nós, se ousarmos, para ver o que está a acontecer-nos" (Sartre 2002, 37). Ora, reconstruindo a situação colonial e as suas representações, Gomes volta o olhar sobre nós.

Certos aspetos da teoria do multinaturalismo ameríndio de Eduardo Viveiros de Castro, método epistemológico aplicado ao cinema por teóricos como Cezar Migliorin, afiguram-se-me importantes instrumentos heurísticos para uma análise do sistema relacionalista proposto por Redemption. Viveiros de Castro distancia-se do mundo ameríndio como objeto de observação para aproximar-se-lhe como sujeito de observação, procurando entrever a realidade a partir de uma perspetiva comum, inconstante e variável no quadro de uma economia geral da alteridade. A primeira carta de Redemption reúne perspetivas múltiplas e como que desencarnadas, devido à particular relação que a vozinha acusmática infantil de Passos Coelho entretece com o bloco de imagens, para logo elaborar um conceito de enunciação expandida, assente numa constante deriva do ponto de vista. A enunciação expandida interroga e mina, desde dentro, a própria representação em ato de fazer-se. O ponto de vista é flutuante e fulgurante: é-o não só graças à multitemporalidade e à multiespacialidade narrativas, mas também porque se desfaz e multiplica em perspetivas que complexificam a relação entre a história e a ficção, o real e o artifício. O sistema narrativo do filme agencia perspetivas e, com elas, diferentes espaços-tempos subjetivos: a Angola colonial e revolucionária, o Portugal revolucionário e europeísta e, entre ambos, os incessantes movimentos de UNESC, Criciúma, v. 5, n¹, janeiro/Junho 2016. Criar Educação - PPGE - UNESC 


\section{Criar Éducaçãa}

desterritorialização. O filme debruça-se precisamente sobre o agenciamento de pontos de vista - o que é isso de um olhar? E como se agencia, no interior de um sistema audiovisual de representação, a passagem entre pontos de vista? Quem vê o quê? Quem vê quem e como? Há ainda os movimentos de passagem entre pontos de vista, um espaço intersticial que envolve o espectador. Sem estar em causa um ocidentalismo nem uma rotação de $360^{\circ}$ à la Juan Downey, o sistema narrativo do filme funda-se na circulação, inconstância e permuta de pontos de vista construído pela montagem e pela relação entre a voz-off e as imagens.

Não está em jogo um retorno nostálgico ao passado colonial africano. Inversamente, trata-se de levar a cabo uma representação crítica - e, se quisermos, exotizada ou africanizada - da ruralidade portuguesa, o que acontecia já em Meu querido mês de agosto (2008). Não só os topoï coloniais são redistribuídos espáciotemporalmente, como emergem imprevistas constelações audiovisuais, um espaço crítico a partir do qual as representações do colonialismo podem ser repensadas, e do qual advém uma reflexão sobre o estatuto da imagem no capitalismo tardio. Desse processo, emerge uma sintomatologia do presente, o que permite, entre outras coisas, inscrever estrutural e historicamente a crise, passo essencial para a sua desconstrução. Perfila-se também uma antropologia do "mesmo" e uma antropologia do poder como partilha do espaço de representação e dissolução das hierarquias enunciativas, o que são estratégias de resistência ao consenso histórico e à ordem discursiva.

O primeiro segmento de Redemption convoca e aproxima a história política do País e a biografia de Passos Coelho, tal como a história do cinema e das formas cinematográficas. A montagem junta imagens de filmes familiares amadores e planos de obras incontornáveis do cinema português, como Esplendor Selvagem (1972), de António de Sousa, Falamos de Rio de Onor (1974), de António Campos, e Máscaras (1976), de Noémia Delgado. A intertextualidade do segmento reside, pois, não só nas imagens, em Super 8, Super $16 \mathrm{~mm}$ e $16 \mathrm{~mm}$, que o filme integra e apropria, devora, como também na filmografia e nos movimentos cinematográficos que convoca. Em Paraíso Perdido (19921995), de Alberto Seixas Santos, que é, a meu ver, o primeiro filme a trabalhar o imaginário colonial português, Cristina (Maria de Medeiros) e Cristovão (Rui Mendes) vão ao cinema ver Esplendor Selvagem, situação espectatorial que se repete em Tabú (2012). No filme de Seixas Santos, os murmúrios e os olhares cruzados dos espectadores ligam Esplendor Selvagem às suas próprias experiências africanas e imprimem um duplo olhar UNESC, Criciúma, v. 5, nº1, janeiro/Junho 2016. Criar Educação - PPGE - UNESC 


\section{Criar Éducaçãa}

às imagens, olhar que as ressubjectiviza. A relação entre o campo - as imagens projetadas de Esplendor Selvagem - e o contra-campo - os espectadores de cinema vendo o filme -, nivelada pela montagem, encontra expressão, em Redemption, na aproximação indeterminada de espaços-tempos equidistantes, na sequência de abertura, por exemplo. Há ainda outro tipo de igualação: entre o "grande" cinema e o cinema "pequeno", a "grande" história e a história "pequena".

Falamos de Rio de Onor e Máscaras inserem-se no movimento etnográfico português das décadas de 60 e 70 e num retorno à terra, ao mundo rural, "uma vontade de ir ao encontro de uma realidade popular" (Afonso e Sapeta Dias 2011, cix), citando José Manuel Costa. Falamos de Rio de Onor inspira-se, tal como Vilarinho das Furnas (1972), numa monografia de Jorge Dias (Rio de Onor, Comunitarismo Agro-pastoril, 1953) sobre o comunitarismo agropastoril da aldeia. ${ }^{3}$ O filme debruça-se sobre a visita de uma mulher da cidade para ver com os seus próprios olhos o que fora descrito vinte anos antes pelo antropólogo. A narração oscila entre a experiência subjetiva, a dramatização e a representação etnográfica da vida na aldeia. Máscaras baseia-se na monografia Máscaras Portuguesas (1973), de Benjamim Pereira, consagrada às Festas dos Rapazes e de Santo Estêvão, em Trás-os-Montes. Na sua tese de doutoramento, Catarina Alves Costa afirma que, com o filme, Delgado reativou, nalgumas aldeias, as desaparecidas festas do ciclo de inverno. Em Rio de Onor, a celebração é "recriada" para o filme, diz a voz-off de Alexandre O'Neill, com "velhos fazendo de novos", tal como, em Bragança, a perseguição da Morte e do Diabo, tradição já extinta em 1975, é representada através de "uma tentativa de reconstituição", cujas imagens reaparecem em Redemption.

Redemption realiza um détour: não se trata já de uma partida para o campo nem de uma deslocação geográfica, não se trata já de inventar um povo. Há, sim, uma deriva histórica e uma passagem do documentário à ficção documental através do discurso e da imagem de outrem. O povo está indiretamente presente através das imagens do passado e das ficções dos seus governantes, e o perspetivismo enunciativo, dominado pela inconstância relacional das formas enunciativas, cria um sistema horizontal de enunciação, redefinindo, ao mesmo tempo, o filme de arquivo como género, sobretudo no que respeita à relação entre a voz-off e a polissemia da imagem.

3 Alguns anos depois, Dias viria a estudar os Macondes de Moçambique, substituindo o interior de Portugal pelo Moçambique rural como terreno de investigação.

UNESC, Criciúma, v. 5, n¹, janeiro/Junho 2016. Criar Educação - PPGE - UNESC 


\section{Criar Éducaçãa}

Em Séméiotiké. Recherches pour una sémanalyse, Julia Kristeva desenvolve a noção bakthiniana de intertextualidade, introduzindo o conceito de "espaço textual múltiplo", o "espaço intertextual" (Kristeva 1969, 255): "o enunciado poético é um subconjunto de um conjunto maior que é o espaço dos textos aplicados ao nosso conjunto" (Kristeva 1969, 255). O texto poético seria, então, elaborado através da "absorção de uma multiplicidade de textos (de sentidos)" (Kristeva 1969, 255), absorção que conteria o momento "negativo" de destruição criativa daqueles textos no espaço intertextual. No espaço intertextual de Redemption, a absorção de imagens comporta um momento de destruição inventiva: um lampejo de redenção, afastando-me da aceção teológica da palavra, em que novos sentidos emergem da fricção semântica e da polissemia das imagens, sendo depois estabilizados pela voz-off. A deriva da enunciação e a fusão entre o ponto de vista subjetivo e o ponto de vista objetivo através do choque entre a imagem, a voz e, por vezes, o som (os tambores da abertura) criam situações enunciativas próximas do discurso indireto livre.

Gomes compõe um anarquivo. Anarchos é o nomen agentis de archein, significando "a ausência de um líder" ou, ainda, a "ausência de disciplina" (Zielinski 2006, 27). A missiva de um futuro líder político converte-se, através da montagem e do complexo jogo multitemporal e multiespacial, em composição poética da desordem. 0 conceito de "anarquivo" baseia-se na noção de "anarqueologia", de Rudi Visker, cunhada a partir da "arqueologia" de Michel Foucault, método epistémico de descrição sistemática de um discurso-objeto, termo aqui combinado com o prefixo "anarchos". Visker define a "anarqueologia" como "um método que recusa identificar o objeto padronizado de uma experiência original" (Zielinski 2006, 27). O anarquivo abrir-se-ia, portanto, a estratégias e interpretações combinatórias e múltiplas. A complexidade da experiência colonial é dada, em Redemption, através da unificação discursiva de fragmentos temporal e materialmente deslocados, bem como de uma geografia formativa e afetiva que se não confunde com uma geografia do poder, mas que ao contrário aponta para a possibilidade de uma redistribução - enunciativa e efetiva - das relações de poder e, nomeadamente, das relações de poder cinematográficas, o que a escolha de arquivos e a ausência de imagens filmadas desde logo indicia.

Redemption convoca ainda outros filmes, como O Parto (1975-1980) e Vinte e cinco (1975-1977), de José Celso Martinez Corrêa e Celso Luccas, o primeiro produzido pela RTP em 1975 para assinalar o primeiro aniversário da Revolução de Abril; o UNESC, Criciúma, v. 5, n¹, janeiro/Junho 2016. Criar Educação - PPGE - UNESC 


\section{Criar Éducaçãa}

segundo, uma encomenda do Governo provisório moçambicano em coprodução com o INA francês, filmado aquando da independência do País. O Parto regista o nascimento de um bebé de Abril, alegoria do complicado nascimento de uma Revolução e do cinema revolucionário. Em Redemption, são apropriados planos do parto de um bezerro no luscofusco de um estábulo transmontano. Alegorizam tais imagens o fim de um cinema, o fim da modernidade do Cinema Novo que talvez se encerre com a geração de Gomes, ou constituem apenas mais uma engrenagem do sistema relacional do filme? Vinte e cinco, por seu turno, representa o nascimento de uma nação, nascimento que coincide, no discurso fílmico, com o nascimento da sua imagem cinematográfica, de um novo olhar, olhar descolonizado, independente da ética e da estética coloniais, assim como dos seus modos percetivos. Os primeiros planos e a mise en scène do ato de ver aproximam Redemption do filme moçambicano de Martinez Corrêa e Luccas .

Na sequência de abertura de Redemption, tal como em certos segmentos de Vinte e cinco, a articulação entre o primeiro plano e o plano subjetivo dissolve a distinção entre o objetivo e o subjetivo e confere à câmara uma presença subjetiva. Ela suspende também a identificação da câmara com a personagem (e, logo, com o espectador), que surge como uma figura da alteridade. O olhar da personagem ocorre como um olhar autónomo ou autonomizado, num devir-outro, num devir coletivo. Para Gilles Deleuze, o discurso indireto livre, cristalizando e formulando a impureza mimética do devir-outro e, desse modo, a impossibilidade de uma individuação equilibrada, é a forma adequada de expressão da alteridade e da coletividade. A proposta de Deleuze é problemática na medida em que solidariza a essência e as formas de expressão, o singular e o universal, evocando a possibilidade de uma representação neutra, questão que também se coloca em Redemption, tanto mais se tomarmos em linha de conta a identidade do protagonista e a possível universalização da sua experiência subjetiva, o que, a meu ver, é obstruído pela deriva enunciativa e pela indeterminação de género.

Tanto O Parto como 25 propõem um sistema de montagem tricontinental, já que a edição, que inclui um vasto e variado acervo de imagens de arquivo, conecta simbolica e culturalmente três territórios separados: Portugal, o Brasil e Moçambique. "Portugal. Brasil. África. Quebrar as barreiras", diz a voz-off do epílogo d'O Parto. Em 25, a vida em Portugal sob o Estado Novo é ilustrada com imagens do arquivo do Instituto Nacional de

UNESC, Criciúma, v. 5, n¹, janeiro/Junho 2016. Criar Educação - PPGE - UNESC 


\section{Criar Éducaçãa}

Cinema moçambicano (INC), fundado em 1976, ${ }^{4}$ do miserável mundo rural português, em que os camponeses do Norte do País aparecem como os colonizados da metrópole. Reencontramos tal deslocação de perspetivas, um ponto de vista em perspetiva, em Redemption, embora fora do quadro do cinema engajado. A mesma aproximação espáciotemporal entre África e Trás-os-Montes, ainda que subordinada ao estado febril da voz-off enunciativa, uma aproximação igualmente entre as máscaras tradicionais transmontanas e as iconografias africanas. Redemption aborda igualmente o modo como as relações coloniais foram transpostas e refeitas no espaço da antiga metrópole e como para aqui foi transferida, segundo Benjamin Stora, a memória do mundo colonial. Se, em Tabú, tal deslocação se operava, invertida, através da personagem de Santa (Isabel Muñoz Cardoso) e, noutra medida, através da personagem da rapariga polaca (Maya Kosa), em Redemption, as oposições são marcadas através da montagem e da voz-off: "eles", diz a voz-off, "os meninos burros e feios de pais alcoólicos", "ela", a professora Minda, "uma hippie", contra "nós", os bons colonos. Tais oposições, insuportáveis do ponto de vista do "politicamente correto", emergem no seio de um sistema, fluido e flexível, em que é o colonizador - e o seu discurso - a ser visto, a ser, com Viveiros de Castro, sujeito que volta sobre si o olhar e objetoobjecto de observação, e atente-se na riqueza do texto, pleno das expressões socioletais daqueles que fizeram o retorno. É também do choque semântico, da multiplicação de pontos de vista e, sobretudo, das relações que dali emergem que desaparece, explodindo em posições enunciativas múltiplas, a rígida separação entre o sujeito da enunciação e o sujeito do enunciado, entre o sujeito e o objeto de observação. É uma antropologia do mesmo lavrada como antropologia do outro

Em 25, a relação entre a colónia e a metrópole tornava-se triádica: vinha juntar-seIhe a "super-metrópole", o "inimigo principal", os EUA. Em Redemption, o pensamento das relações coloniais articula-se com uma reflexão sobre a crise. Antes de mais, a Revolução portuguesa é dada como o segundo momento de outra revolução, a "revolução anticolonial" (Varela 2014, 110), termo de Raquel Varela. Por outro lado, usando a terminologia de Boaventura de Sousa Santos, a representação do início do "momento neocolonial europeu" (Sousa Santos 2011, 421-428) após 1974, cruza-se em Redemption com a do seu declínio, com a "contrarrevolução imposta pela troika" (Sousa Santos, 2013), citando ainda o sociólogo. O filme de Gomes é, aliás, expressivo formalmente do

4 O Serviço Nacional de Cinema (SNC) precede o INC e é fundado em novembro de 1975, apenas cinco meses depois da independência.

UNESC, Criciúma, v. 5, n¹, janeiro/Junho 2016. Criar Educação - PPGE - UNESC 


\section{Criar Éducaçãa}

"complexo palimpsesto" (Sousa Santos 2011, 434), descrito por Sousa Santos, "de temporalidades e inter-identidades envolvendo a zona Europeia e a zona colonial... em que os diferentes períodos se acomodaram em formas diferentes e imprevisíveis, sempre presentes" (Sousa Santos 2011, 404). Redemption é um filme-palimpsesto em que convivem transversal e metonimicamente espaços e tempos múltiplos, formas e períodos cinematográficos, e em que a deriva e o perspetivismo enunciativos fazem com que emirjam camadas profundas e esquecidas - e que outras desapareçam. A deriva do ponto de vista não deve ser confundida com uma ausência de ponto de vista: a política do filme está na relação, na transformação do "mesmo" em "outro" e do "aqui" em "ali" e, sobretudo, naquilo que ocorre nessa transação, nessa passagem indeterminada entre o "mesmo" e o "outro", o "aqui" e o "ali", o "paraíso luso-tropical" de Gilberto Freyre e "a terra da agonia" do poema de Mutimati Barnabé João, heterónimo de António Quadros.

UNESC, Criciúma, v. 5, n¹, janeiro/Junho 2016. Criar Educação - PPGE - UNESC 


\section{Criar Éducaçãa}

\section{Bibliografia}

Afonso, Tiago e Sapeta Dias, Inês. 2011. Documentário no Pós-Abril. Os Anos 70 na História do Cinema Português (e seus Parêntesis). Conversa com José Manuel Costa. Catálogo do Panorama, $5^{\text {a }}$ Mostra do Documentário Português. Lisboa: Apordoc.

Alves Costa, Catarina Sousa Brandão. 2012. "Camponeses do Cinema: a Representação da Cultura Popular no Cinema Português entre 1960 e 1970." Diss. de Doutoramento, Universidade Nova de Lisboa.

Bakhtin, Mikhaïl. 1992 (1929). Marxismo e Filosofia da Linguagem. São Paulo: Hucitec.

"Boaventura de Sousa Santos alerta para contrarrevolução imposta pela troika". Jornal Y, 24 de Janeiro de 2013, acedido a 30 de Agosto de 2014.

Cabral, Amílcar. 1969. Prefácio a The Liberation of Guiné: Aspects of an African Revolution, de Basil Davidson. Harmondsworth, Baltimore e Ringwood: Penguin.

Cardoso, Maria Dulce. 2012. O Retorno. Lisboa: Tinta-da-China.

Chion, Michel. 2005. L'audio-Vision : Son et image au cinéma. Paris: Armand Colin.

Deleuze, Gilles. 1985. Cinéma 2. L'Image-Temps. Paris: Minuit.

Deleuze, Gilles et Guattari, Félix. 1972. Capitalisme et schizophrénie 1 : L'anti-CEdipe.

Paris: Minuit.

Dias, Jorge. 1953. Rio de Onor. Comunitarismo Agro-Pastoril. Porto: Instituto de Alta Cultura, Centro de Estudos de Etnologia Peninsular.

Dias, Jorge. 1964. Os Macondes de Moçambique, I, Aspectos Históricos e Económicos. Lisboa: Junta de Investigação do Ultramar.

Dias, Jorge e Dias, Margot. 1964. Os Macondes de Moçambique, II, Cultura Material. Lisboa: Junta de Investigação do Ultramar.

Dias, Jorge e Dias, Margot. 1970. Os Macondes de Moçambique, III, Vida Social e Ritual. Lisboa: Junta de Investigação do Ultramar.

Dias, Jorge e Viegas Guerreiro, Manuel. 1966. Os Macondes de Moçambique, IV, Sabedoria, Língua, Literatura e Jogos. Lisboa: Junta de Investigação do Ultramar.

Fanon, Frantz. 2002 (1961). Les damnés de la terre, de Frantz Fanon. Paris: Maspero.

Fanon, Frantz. 1971. Peau noire, masques blancs. Paris: Seuil.

Flusser, Vilém. 1998. Ensaio sobre a Fotografia. Para uma Filosofia da Técnica. Lisboa: Relógio

d'Água.

Foucault, Michel. 2010. L'archéologie du savoir. Paris: Gallimard.

Freyre, Gilberto. 2010. O Mundo que o Português Criou. São Paulo: É Realizações. João, Mutimati Barnabé. 2008 (1975). Eu, o Povo [Texte imprimé]. Lisboa: Cotovia.

Kristeva, Julia. 1969. Semeiotiké : recherches pour une sémanalyse. Paris: Seuil.

Migliorin, Cezar. 2012. "Perspectivisme : La construction du point de vue." In Cinéma, critique des images, editado por Claudia d'Alonzo, Ken Slock e Philippe Dubois. Pasian di Prato: Campanotto Editore.

Pereira, Benjamin Enes. 1973. Máscaras Portuguesas. Lisboa: Junta de Investigações do Ultramar, Museu de Etnologia do Ultramar.

Sartre, Jean-Paul. 2002 (1961). Prefácio a Les damnés de la terre. Paris: Maspero.

Sousa Santos, Boaventura. 2011. "Portugal: Tales of Being and Not Being." In Facts and Fictions of António Lobo Antunes, editado por Victor K. Mendes, 399-443. Dartmouth: Tagus Press UMass Dartmouth.

Stoler, Ann Laura. 2010. Along the Archival Grain: Epistemic Anxieties and Colonial Common Sense. Princeton : Princeton University Press.

UNESC, Criciúma, v. 5, n¹, janeiro/Junho 2016. Criar Educação - PPGE - UNESC 


\section{Criar Éducaçãa}

Stora, Benjamin.1999. Le transfert d'une mémoire: de l'"Algérie française" au racisme antiarabe. Paris: La Découverte.

Varela, Raquel. 2014. História do Povo na Revolução Portuguesa. 1974-75. Lisboa: Bertrand.

Viveiros de Castro, Eduardo. 2002. A Inconstância da Alma Selvagem e Outros Ensaios de Antropologia. São Paulo: Cosac Naify.

West, Harry G. 2004. "Inverting the Camel's Hump. Significant Others. Interpersonal and Professional Commitments in Anthropology." In History of Anthropology, vol. 10/ editado por Richard Handler. Madison: University of Wisconsin Press.

Zielinski Siegfried. 2006. Deep Time of the Media. Toward an Archaeology of Hearing and Seeing by Technical Means. Cambridge e Londres: Massachusetts Institute of Technology. 